\title{
O PAPEL DA GESTÃO DE FACILITIES NO PROCESSO DE INOVAÇÃO: ESTUDO EXPLORATÓRIO EM UMA INDÚSTRIA AUTOMOBILÍSTICA DO ESTADO DE SÃO PAULO
}

The facilities management role in inovation process: case study on automobile company at São Paulo

Robson Quinello* Ana Elisa Martins Pacheco de Castro**

\section{Resumo}

Para que o processo de inovação ocorra satisfatoriamente é preciso reduzir o seu ciclo de desenvolvimento, de modo a ampliar a vantagem econômica do produto, diluindo mais rapidamente os altos investimentos que cercam qualquer processo de desenvolvimento de novo produto PDNP. Neste sentido, a integração entre as áreas funcionais, core e non core é imprescindível. O objetivo deste artigo é investigar como e em quais momentos a área de apoio e suporte, chamada Gestão de Facilities, termo anglo-saxão que traduziremos para Gestão de Facilidades - GF atua no PDNP em uma indústria do setor automobilístico, descobrindo a importância que este departamento (de serviços) possui em uma empresa orientada à inovação de produtos. Para isso, utilizamos uma pesquisa exploratória do tipo estudo de caso, baseada em documentos, projetos, arquivos e entrevistas advindas de uma unidade localizada em São Paulo.

* Mestre pela Fecap e Doutorando do Programa de Pós - graduação pela Universidade São Paulo FEA. Email: rquinello@uol.com.br

** Aluna Especial da Disciplina “Gestão da Inovação de Produtos e Processos” pela Universidade São Paulo- FEA. Email: anaelisacastro@hotmail.com 
Os resultados mostram que os projetos de facilities são moldados por diversas forças institucionais, conduzidos por mecanismos mais tácitos que formais, no apoio à PDNP e na manutenção da infra-estrutura existente.

Palavras-chave: Inovação. Gestão do conhecimento tecnológico. Gestão de facilities. Operações e serviços.

\section{Abstract}

So that the innovation process occurs satisfactorily it is necessary the development of the cycle reducing, in order to extend the economic advantage of the product, diluting, more quickly, the high investments that surround any development process of a new product development - NPD. In this sense, the integration between the functional areas, core and non-core is essential. The objective of this article is to investigate how and where a support area - facilities management, acts in the $N P D$ in an automobile industry, discovering the importance that this department (services centered) occupies in a company guided to products innovation. For this, we use an descriptive research - case study, based on documents, projects, archives, and interviews in a plant located at São Paulo. The results show that projects are molded by many institutional forces, driven by mechanisms more tacit than formal, both to support NPD and infrastructure maintenance.

Keywords: Innovation. Technological knowledget management. Facilities management. Operation and services

\section{INTRODUÇÃO}

A gestão da carteira de projetos é uma atividade crítica para todas as empresas, uma vez que sustenta a orientação estratégica da empresa e direciona a alocação de recursos de projetos para este fim (ARCHER; GHASEMZADEH, 1999; WHEELWRIGHT; CLARK, 1992; COOPER; EDGETT; KLEINNSCHMIDT, 2001). Estes mesmos autores afirmam que uma carteira bem planejada envolve uma análise detalhada dos fatores externos (aceitação e adequação de produtos, concorrência, senso de 
oportunidade, análise de cenário entre outros) quanto às capacidades internas sejam elas técnicas, produtivas ou ainda de sustentação.

Indústrias mais maduras e com forte apelo tecnológico, como é o caso da automobilística, têm voltado sua atenção não só para seus produtos em si, mas também para o aperfeiçoamento de seus processos internos, isto pode ser observado ao verificarmos as inúmeras ferramentas de desempenho de produtividade utilizadas na unidade da Alfa em São Bernardo do Campo. Este fato foi ratificado em artigo publicado pela Business Week (2006), o qual afirma que os altos investimentos em P\&D não são suficientes para assegurar o sucesso de vendas de automóveis, ou seja, o diferencial competitivo dessas empresas não está relacionado apenas às grandes diferenças de conhecimento tecnológico, mas sim a maneira que cada uma delas gerencia e aperfeiçoa os seus processos internos para desenvolver um novo produto.

Ainda buscando reforçar esta afirmação, citamos a Toyota que, em 2005, assumiu o posto de quarta empresa mais inovadora do mundo, por sua capacidade de desenvolver produtos e processos muitos mais eficientes e eficazes que outras companhias (Business Week, 2006). Em 2006, ao produzir mais de sete milhões de veículos, ela se consolidou como a primeira fabricante mundial de veículos, suplantando as gigantes americanas GM e Ford (OICA, 2007). Esta "ultrapassagem” se deu no mesmo momento em que a Ford aparecia como a maior investidora em P\&D do setor automobilístico (Business Week, 2006).

O objetivo do estudo é explorar o vácuo existente na literatura de inovação, especificamente sobre a relação da gestão em serviços dentro de um processo de inovação em produtos. Para isso, utilizaremos um departamento de apoio de uma automobilística americana (intensiva na tecnologia e gestão de produtos) chamado GF. O escopo da análise é a etapa de desenvolvimento dos produtos de uma das plantas localizadas em São Paulo, ou seja, não serão investigadas as etapas embrionárias da concepção dos mesmos, também chamadas de front-end.

Segundo Mansharamani (2005) diversos autores se esforçaram para desenvolver uma teoria para inovação em serviços, mas a maior dificuldade na sua construção está na natureza deste segmento, caracterizado por 
sua intangibilidade, perenidade, heterogeneidade, simultaneidade, transferibilidade e especificidade.

A área de GF, raramente explorada na literatura sobre inovação, compõe, ainda que informalmente, o complexo elo de desenvolvimento de produtos e serviços dentro de uma indústria automobilística, uma vez que é responsável pela construção e manutenção das infra-estruturas básicas das instalações industriais (QUINELLO; NICOLETTI, 2006). Esta área sustenta e atende às necessidades organizacionais e, por seu caráter normativo, pode facilitar ou restringir o desenvolvimento de novos produtos e serviços por meio de uma gestão de carteira de projetos complexos e diversificados.

Como e em que momento ocorre a relação entre GF e PDNP? Qual o impacto que a gestão de projetos desta área tem no produto final? Para responder estas questões de pesquisa, trataremos nos próximos itens dos conceitos, da gestão de carteira de projetos e gestão de facilities. Logo em seguida, por meio de uma pesquisa exploratória, investigaremos o fenômeno para, por fim, apontar os mecanismos desta dinâmica apresentando os principais pontos desta relação e futuras pesquisas.

\section{GESTÃO DE CARTEIRA DE PROJETOS}

Entende-se por carteira ou portfólio de projetos a somatória de esforços sincronizados voltados à busca de produtos ou serviços capazes de alavancar e sustentar os negócios das empresas. Segundo Archer e Ghasemzadeh (1999), portfólio de projetos são um grupo de projetos concorrentes alinhados à estratégia de negócios da empresa. A seleção do portfólio assume a função de dinamizar periodicamente estes esforços, considerando as restrições, os recursos e o ambiente. Contudo, o processo de decisão das carteiras é incerto e imprevisível, pois manipula informações, oportunidades, metas, estratégias, locações e alocações altamente mutáveis.

Segundo Archer e Ghasemzadeh (1999), os fatores mais relevantes para uma gestão eficiente de carteiras são, não necessariamente nesta ordem, as razões financeiras, o alinhamento estratégico, a comunicação vertical (criando visibilidade e decisão), a comunicação horizontal (criando 
redes de relacionamentos entre áreas), o aumento de objetividade, o aumento de vendas, a participação de mercado e a busca de foco nos negócios.

O sucesso de uma inovação depende do trabalho conjunto de muitas áreas, as quais podem contribuir direta ou indiretamente para o processo. Neste sentido, assumimos que, por similaridade de objetivos, a definição da carteira de projetos destes departamentos são tão cruciais à empresa quanto a escolha do produto/serviço a ser desenvolvido.

No Brasil, o assunto facilities é relativamente novo e controverso dentro da gestão de operações e serviços. A dificuldade para consolidação talvez se dê pela ausência de pesquisadores na área, falta de associações profissionais consolidadas (a British Institute of Facilities Management - BIFM foi fundada em 1993 e a Associação Brasileira de Facilities - ABRAFAC em 2004), de profissionais interessados em relatar suas experiências, da não-normatização da atividade, dos altos custos envolvidos ou até dos próprios profissionais de facilidades atuantes nas organizações (QUINELLO e NICOLETTI, 2006).

Em termos financeiros, de acordo com estudos do BIFM, mais de $50 \%$ dos custos das instalações e construções são destinados às atividades de infra-estrutura (manutenção e operação), demonstrando o papel central na sobrevivência dos negócios das organizações ao longo dos anos. Estes estudos apontaram, sobretudo, as fragilidades estruturais e situação funcional irregular dos profissionais da área, concluindo-se que as atividades "non core” ainda são paradigmas nas organizações em geral, principalmente dentro de operações e serviços, nos quais geralmente são considerados "core" apenas as atividades fim. Por outro lado, tamanha é a importância dada às questões ligadas a área, que na análise SWOT (strenghts, weakness, opportunities and threates) das automobilísticas Toyota e DaimlerChrysler são apontadas novas pesquisas em facilities e novas localidades como oportunidades de crescimento e sustentação dos negócios para o século XXI. Para estas empresas, localizar e manter novos pontos estratégicos ajuda a buscar competências tecnológicas e a criar novos mercados, pois se estabelecem novas fronteiras que abarcam novos clientes (DATAMONITOR, 2005). 


\section{METODOLOGIA}

Quanto ao método utilizado na presente pesquisa, de acordo com a classificação apresentada por Cooper e Schindler (2003), levou-se em consideração os seguintes critérios:

- A questão de pesquisa é como e em que momento a gestão de facilities auxilia a gestão de novos produtos e, por meio de um estudo de caso exploratório, oferecer uma visão aproximada e preliminar do fenômeno. As pesquisas qualitativas, de acordo com EasterbySmith et al. (1999), permitem ao pesquisador, uma vez próximos dos membros de uma organização, obter um melhor discernimento sobre as pessoas e situações que estão sujeitas, além de auxiliar os respondentes a construírem, às vezes pela primeira vez, suas realidades.

- Em relação à dimensão tempo, a pesquisa foi caracterizada como transversal, de modo que representou uma foto instantânea no tempo.

- O método de coleta de dados é observacional, formatado sobre entrevistas semi-estruturadas com os profissionais da área, análise da carteira de projetos de GF, documentos e registros históricos (fontes e nomes foram preservados para não expor conteúdos estratégicos da empresa ou materiais confidenciais), criando uma triangulação de vários tipos de métodos e fontes, enriquecendo e fortalecendo as considerações extraídas do caso.

- A respeito do controle das variáveis, a pesquisa é ex post facto e descritiva, ou seja, não foi exercido controle sobre as variáveis investigadas apenas relatou-se o que foi observado na empresa.

- Quanto ao escopo ela é do tipo estudo de caso, não tendo preocupação com amplitude e, sim, profundidade, uma vez que enfatizou uma análise contextual de um número menor de eventos. Ressaltamos que o estudo de caso consiste em uma investigação profunda, no decorrer de certo tempo, permitindo uma análise processual, contextual e de 
significados de um determinado fenômeno. Ainda quanto ao escopo, procuramos investigar as fases de desenvolvimento e execução dos projetos de facilities no apoio ao desenvolvimento de novos produtos, pois a empresa em questão é uma das filiais e não tem controle sobre a definição e concepção da carteira de projetos da matriz.

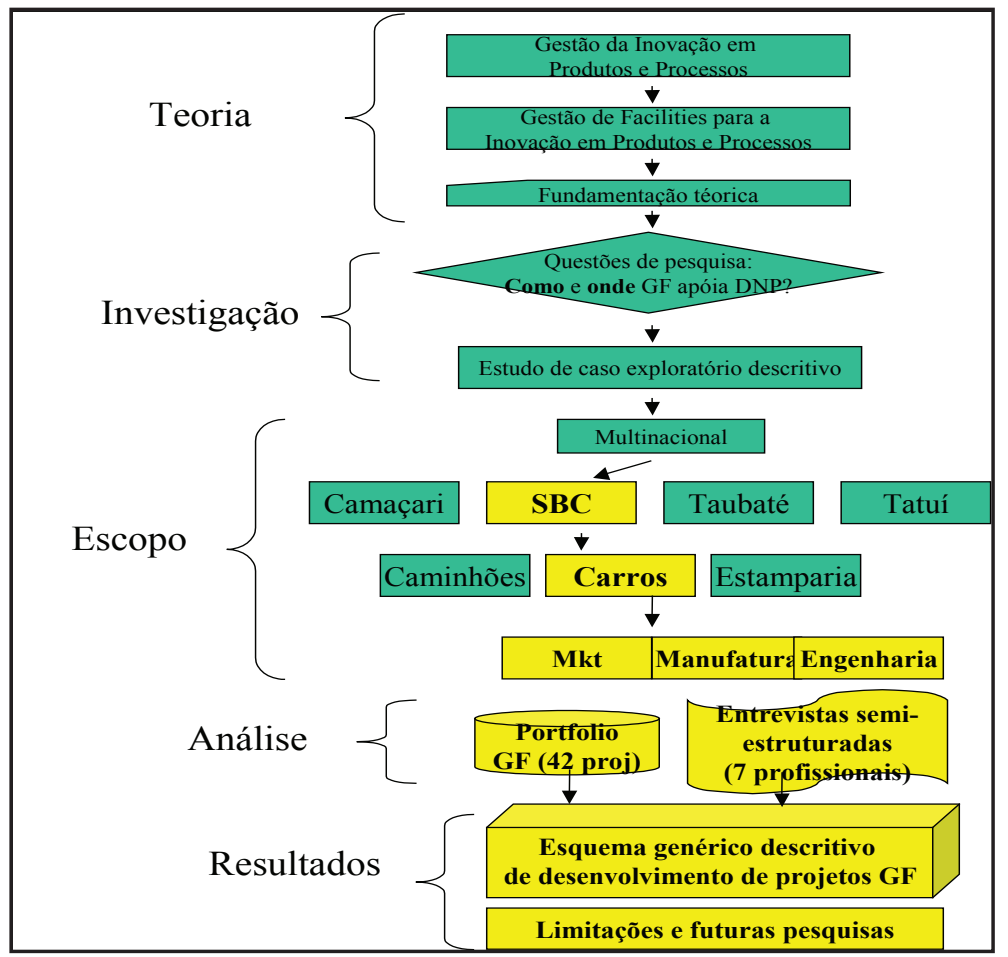

Figura 1 -Metodologia do caso

Fonte: Elaborado pelos autores

No questionário optou-se por questões semi-estruturadas, pois para Easterby-Smith et al. (1999), este é o caminho indicado quando o pesquisador não tem muito tempo disponível do entrevistado e quando se sabe muito bem aquilo que busca, parâmetros ajudam a focar e agilizar as entrevistas. As questões elaboradas para este estudo tiveram como base 
as proposições de Clark e Wheelwright (1992), focando principalmente o contexto, as práticas, os desafios e as ações de gestão de projetos de facilities no apoio os novos produtos da empresa objeto de estudo. As entrevistas (sete) foram realizadas no escritório central, no Grande ABC, não havendo interferência ou obstrução direta dos entrevistadores durante as sessões individuais (em torno de 1 hora cada). Inicialmente as propostas do estudo foram claramente explicadas a cada participante e argüiu-se sobre as atividades e funções de cada entrevistado, analisando o contexto e a rotina de trabalho de cada um. Em seguida, questões semi-estruturadas procuraram aprofundar o entendimento do entrevistado sobre a gestão de desenvolvimento de projetos de facilities no apoio ou não aos produtos da empresa, sua participação nesta dinâmica, suas dificuldades, suas expectativas e pontos de vista. Houve um polimento das entrevistas após duas semanas com alguns entrevistados, por meio de contato telefônico, para aprimorar as repostas.

Outra fonte de dados, documental, foi à análise da carteira de projetos da área, composta por 42 projetos contemplando as estratégias de negócios do período 2007-2012. A previsão para investimentos nos próximos anos passa de 70 milhões de reais, demonstrando a participação significativa da área para os negócios da empresa. Por questões de confidencialidade, o conteúdo dos projetos não será revelado, até porque o foco da pesquisa está na relação entre as atividades de GF com PDNP e não na natureza específica dos mesmos. A carteira de GF está dividida em variáveis categóricas independentes: categoria, prioridade, natureza (forças institucionais), complexidade técnica, tempo e valor. A variável proximidade com $P$ DNPé dependente e foi criada após as análises das demais, como mostra o quadro abaixo.

No Quadro 1 é possível verificar as relações entre as variáveis utilizadas na elaboração da carteira de projetos de facilities com o PDNP. Para esta relação, optamos por uma análise de clusters (HAIR et al., 1998), também conhecida como análise de conglomerados (os softwares estatísticos utilizados foram o Minitab 14 e o BioStat 4). Trata-se de um conjunto de técnicas estatísticas, cujo objetivo é agrupar objetos de características semelhantes, formando grupos ou conglomerados 
revista tecnologia e sociedade

\begin{tabular}{|c|c|c|c|c|c|c|}
\hline \multicolumn{6}{|c|}{ VARIÁVEIS INDEPENDENTES } & \multirow{2}{*}{$\begin{array}{c}\text { VARIÁVEL } \\
\text { DEPENDENTE } \\
\begin{array}{c}\text { Proximidade } \\
\text { com PDNP }\end{array}\end{array}$} \\
\hline Categoria & Prioridade & $\begin{array}{c}\text { Natureza } \\
\text { (fonte) }\end{array}$ & $\begin{array}{c}\text { Complexid } \\
\text { ade } \\
\text { Técnica }\end{array}$ & $\begin{array}{l}\text { Tempo } \\
\text { (Prazo) }\end{array}$ & $\begin{array}{c}\text { Valor } \\
\text { (R\$ } \\
\text { 000) }\end{array}$ & \\
\hline $\begin{array}{l}\text { 1-LEGAL } \\
\text { 2-UTILIDADE } \\
\text { 3-SEGURANÇA } \\
\text { 4-AMBIENTAL } \\
\text { 5-OUTROS } \\
\text { 6-REABILITAÇÃO } \\
\text { 7-CONSTRUÇÃO } \\
\text { 8-MELHORIAS }\end{array}$ & $\begin{array}{l}\text { 0-CRITICO } \\
\text { 1-ALTO } \\
\text { 2-MÉDIO } \\
\text { 3-BAIXO }\end{array}$ & $\begin{array}{l}\text { 1-MIMÉTICO } \\
\text { 2-NORMATIVO } \\
\text { 3-COERCITIVO }\end{array}$ & $\begin{array}{l}\text { 1-ALTA } \\
\text { 2-MÉDIA } \\
\text { 3-BAIXA }\end{array}$ & $\begin{array}{l}\text { 1-CURTO } \\
(2007-2008) \\
2-\text { MÉDIO } \\
(2009-2010) \\
3-\text { LONGO } \\
(2011-2012)\end{array}$ & $\begin{array}{l}\text { VALOR } \\
\text { DO } \\
\text { PROJE } \\
\text { TO }\end{array}$ & $\begin{array}{l}\text { 1- MUITO ALTA } \\
\text { 2- ALTA } \\
\text { 3- RAZOÁVEL } \\
\text { 4-BAIXA } \\
\text { 5-MUITO BAIXA } \\
\text { 6-NULA }\end{array}$ \\
\hline
\end{tabular}

Quadro 1 - Variáveis categóricas da carteira de projetos de facilities.

homogêneos. Os objetos de cada conglomerado são semelhantes entre si e diferentes dos demais grupos. Os conglomerados obtidos devem apresentar tanto uma homogeneidade interna (dentro de cada conglomerado), como uma grande heterogeneidade externa (entre conglomerados). Portanto, se a aglomeração for bem sucedida, quando representados em um gráfico (usualmente o dendograma), os objetos dentro dos conglomerados estarão muito próximos, e os conglomerados distintos estarão afastados.

A análise de cluster é uma técnica do tipo de interdependência, pois não é possível determinar antecipadamente as variáveis dependentes e independentes. Em um primeiro momento, utilizou-se o método de Ward (método de variância, derivado de um processo hierárquico e aglomerativo). No processo aglomerativo cada objeto tem início em um conglomerado separado. Formam-se os conglomerados agrupando-se os objetos em conglomerados cada vez maiores. No método de variância, os conglomerados são gerados de modo a minimizar a variância dentro do conglomerado. Finalmente, no método de Ward, o objetivo é minimizar o quadrado da distância euclidiana às médias dos conglomerados. Segundo Malhotra (2001), os processos formais de avaliação da confiabilidade e validade de soluções de conglomerados são complexos e nem sempre totalmente defensáveis. Utilizamos para esta análise uma similaridade de mínimo 60\%, assegurando blocos mais coesos.

Posteriores as duas análises, das entrevistas e da carteira de projetos, buscaremos as relações entre os dois instrumentos utilizados propondo um framework ou esquema genérico da participação da gestão de facilities na gestão de novos produtos. 


\section{o papelda gestão de facilities...}

\section{DISCUSSÃO E ANÁLISE DO CASO}

Assim como a maior parte das automobilísticas, a empresa analisada possui um esquema formal para o PDNP aliando as estratégias de negócios das áreas de marketing, engenharia e manufatura. Trabalha com times estruturados e integrados, liderados por um gerente de projetos, num modelo parecido com o que Clark e Wheelwright (1992) chamam de heavyweight team. As plantas não têm autonomia na concepção e na tomada de decisão final sobre qual o produto a ser fabricado nas mesmas. Porém, um fator que pode restringir a vinda de um produto é a infra-estrutura básica e operacional (manufaturabilidade) da unidade (atribuições específicas de GF), além de outros aspectos políticos e institucionais não explorados nesta pesquisa.

O esquema de PDNP é formado por diversas etapas como alocação de recursos, decisões técnicas e estratégicas, aprovações, prototipagens até a validação final para a produção em escala, conforme Figura 2.

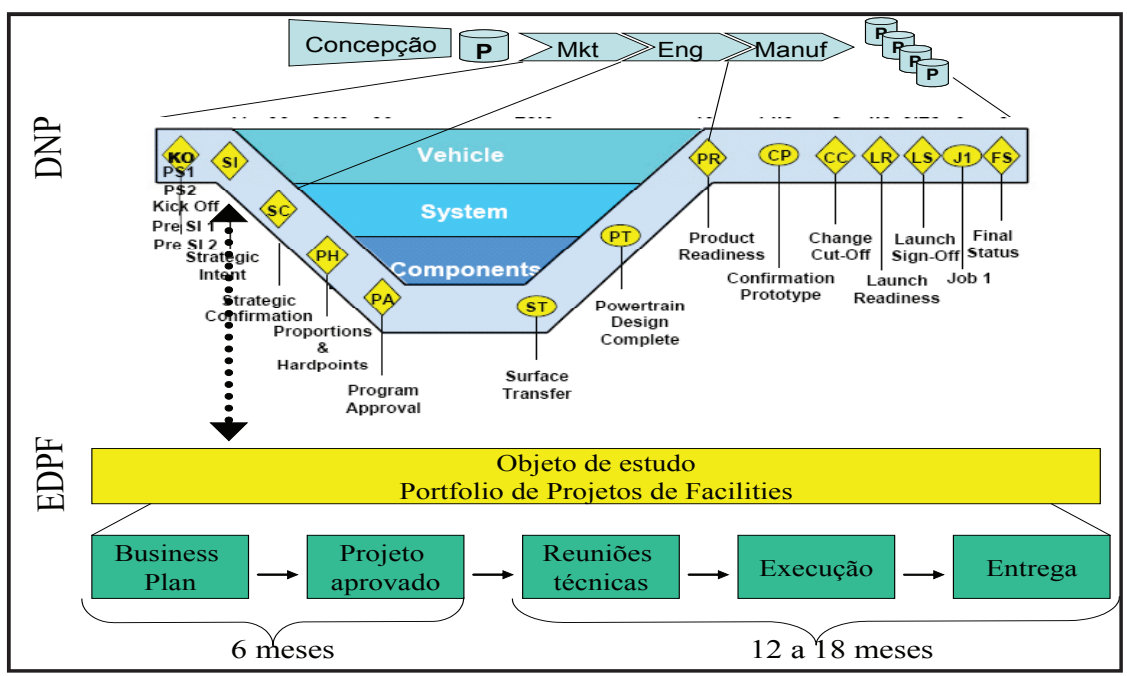

Figura 2 - Esquema de PDPN

Fonte: Elaborado pelos autores 
GF é acionada na fase de "intenções estratégicas" (SI), na qual todos os envolvidos solicitam verbas e apontam suas restrições ao novo projeto. Ela auxilia o processo com um esquema informal próprio de portfolio de projetos. Cada projeto é composto por cinco fases principais - desenvolvimento do plano de negócios (defesa do projeto), aprovação, reuniões técnicas de avaliação, execução dos projetos e entrega para 0 usuário. Este processo pode durar até 24 meses entre a solicitação e a entrega final (contando com os retrabalhos).

\section{Carteira de projetos de GF}

A carteira de projetos de GF, analisada na unidade de São Bernardo do Campo - São Paulo, era composta por 42 projetos e, anualmente, todos os departamentos funcionais da empresa teriam a responsabilidade de planejar e coordenar as atividades que comporiam o planejamento de negócios das operações da planta. Independente da introdução de novos produtos na unidade, todos examinam internamente suas necessidades e demandas (até mesmo para manterem os produtos existentes) para depois iniciarem seções de priorização de projetos com toda a diretoria e gerência chegando na formação final da carteira de projetos.

GF possui uma carteira de projetos que totaliza, para o exercício de 2007-2012, 120 projetos, distribuídos entre as quatro plantas brasileiras o departamento recebe diversas solicitações de todas as áreas das unidades sem nenhum processo formal. As pressões atuantes nestes projetos são tanto de naturezas normativas (forças advindas da profissionalização e da técnica), coercitivas (leis, regulamentos, procedimentos, estruturas, reclamações dos clientes internos e comunidade, comissão de fábrica, sindicato etc.) e mimética (novas tecnologias e ajustes nas instalações para atender produtos novos e existentes), emprestando os termos da escola neo-institucionalista de Powell e DiMaggio (1991). O portfolio é um misto entre check-list, plano estratégico e modelo de ranqueamento, corroborando com os modelos mais usuais apresentados por Cooper, Edgett e Kleinschmidt (2001). Este portfolio, como já mencionado, está classificado em variáveis categóricas independentes como: categoria, prioridade, natureza, complexidade técnica e tempo. 


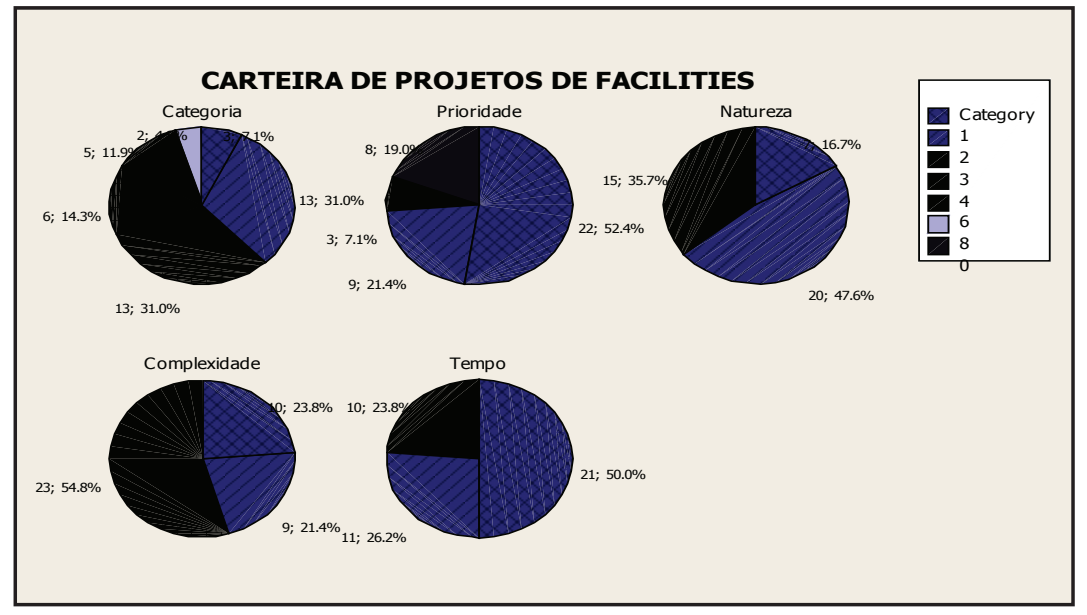

Gráfico 1 - Categorias do portfolio de projetos.

\section{Composição da carteira de projetos de GF na unidade estudada}

A pesquisa nos mostrou que $62 \%$ da carteira está destinada à projetos de incremento das utilidades e melhoria da segurança, demonstrando a preparação e enfoque da planta para a nova plataforma de 2008. Na Gráfico 1 - Categorias do portfolio de projetos.

entrevista verificamos que o valor destinado à manutenção da infra-estrutura, nos últimos anos, não ultrapassa $1 \%$ do valor dos ativos (de acordo com pesquisas da Associação Brasileira de Manutenção - ABRAMAN, 2003), o valor praticado pelo mercado varia entre $3 \%$ a $5 \%$ (do valor do ativo). Esta estratégia de contenção de custos, como podemos observar, fragilizou e onerou as instalações industriais ao longo dos anos, o que reflete na carteira atual de projetos da área (apenas 16\% dos projetos são para reabilitações e melhorias). Com relação à categoria segurança, notamos uma preocupação interna para com as questões relacionadas à saúde, segurança e qualidade de vida dos empregados (provavelmente em função das forças coercitivas advindas de um ambiente altamente sindicalizado).

Os projetos, no geral, têm prioridade considerada máxima (mais de $50 \%$ são críticos) e 23,8\% são considerados extremamente complexos. $\mathrm{Na}$ categoria tempo, metade é de curta duração, ou seja, serão realizados 
entre 2007 e 2008, denotando a pressa em adequar a planta às novas plataformas. Eles nascem, sobretudo, de forças coercitivas $(59,5 \%)$, isto é, as pressões são, principalmente, de naturezas legais e normativas, levando a crer que a empresa está num ambiente de vigilância intensiva.

Como previsto, a alocação de recursos foi priorizada para projetos de segurança e questões ambientais (R\$ 52 milhões ou 70\% do total). Os demais - legais, reabilitações, melhorias e utilidades têm verbas estimadas em $\mathrm{R} \$ 24$ milhões, ratificando o cenário complexo no qual a organização está inserida.

Após a análise descritiva dos projetos, partimos para uma análise conjunta de todas as variáveis independentes na tentativa de descobrir aglomerados específicos. Por meio da análise de cluster, dendograma da Figura 1, notamos subgrupos com similaridades maiores de 60\% que estão relativamente próximos ao PDNP. Os aglomerados localizados ao lado esquerdo da Figura 1 possuem forte relação no desenvolvimento de novos produtos, pois são projetos que afetam diretamente a capacidade de produção da planta. Alguns exemplos: projeto para pós-queima de gases liberados pela pintura que forçará o desenvolvimento de novas tintas e instalação de queimadores de gases, instalação de parque de combustíveis alternativos que alimentarão os veículos para exportação e adequação da subestação elétrica para garantir a operacionalidade e cargas elétricas da nova linha de montagem. À medida que os blocos se afastam para o lado direito da Figura 3, eles ficam distantes e pouco interferem no PDNP.

Após análise dos clusters, pode-se reorganizar os projetos de acordo com a proximidade com o PDNP, notando que os mais próximos $(14,3 \%)$ representam a minoria. Este cenário demonstra uma certa distância entre as atividades de facilities e as áreas de desenvolvimento de produtos, levando a crer que a área possui limitação e pouca penetração nas estratégias da alta administração.

Com relação às correlações entre as variáveis independentes complexidade, prioridade, categoria, natureza e tempo com a variável dependente proximidade de DNP, utilizando o coeficiente de Spearman para amostras não-paramétricas de nível ordinal (LEVIN, 1987). Para a variável valor, de nível intervalar, optou-se pelo teste $r$ de Pearson. 
o papeldagestão de facilities...

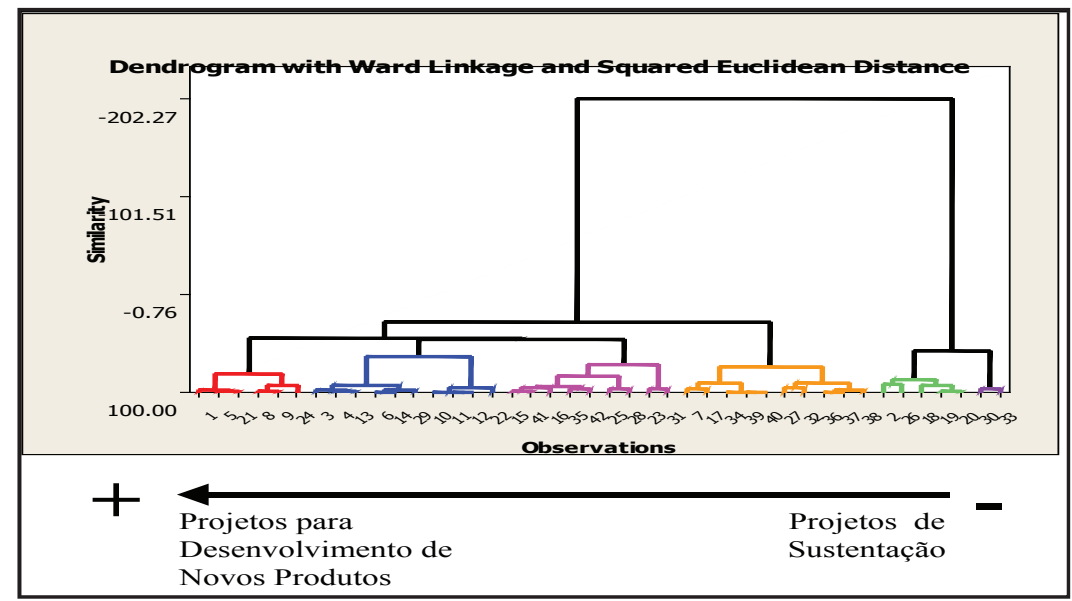

Figura 3- Análise de cluster da carteira de projetos de facilities Fonte: Elaborados pelos autores, software Minitab 14.

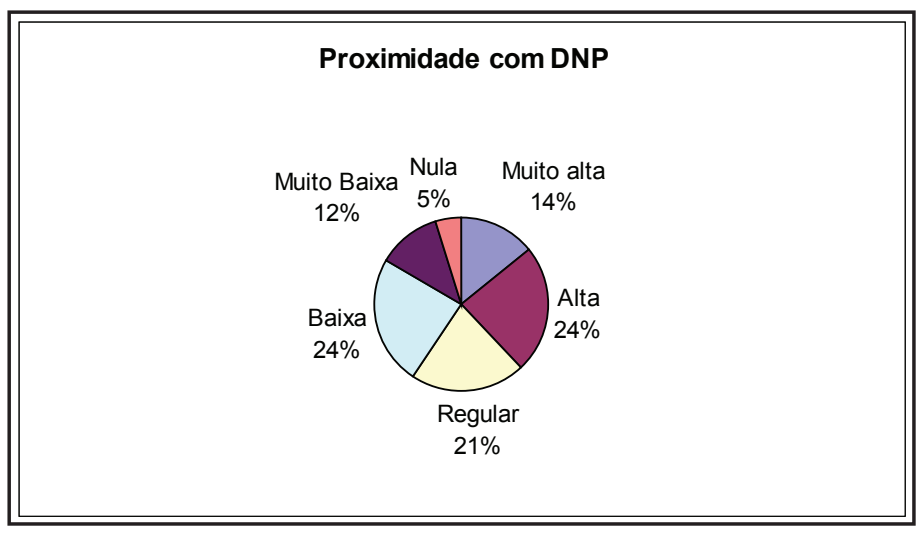

Gráfico 2 - Proximidade de GF com DNP

Observou-se correlação moderadamente positiva $(>0,30)$ significativa ( $\mathrm{p}$-value $<0.05$ ) nas variáveis prioridade e complexidade. Isto demonstra que ambas aumentam conforme a aproximação com DNP. As demais variáveis não apresentaram correlações significativas. Este resultado ratifica a falta de processo de priorização no portfolio de projetos, revelando uma 
possibilidade de melhoria na alocação dos recursos nos projetos mais críticos para PDNP.

\begin{tabular}{|c|c|c|c|}
\hline Variável & $\begin{array}{l}\text { Coef. Spearman } \mathrm{r}^{2} \\
\text { (não-paramétrico / } \\
\text { ordinal) }\end{array}$ & p-value & Resultado \\
\hline Categoria & 0,09 & 0,54 & $\begin{array}{c}\text { Não há diferença significativa entre as } \\
\text { amostras }\end{array}$ \\
\hline Prioridade & $\mathbf{0 , 3 9}$ & $\mathbf{0 , 0 1}$ & $\begin{array}{c}\text { Há diferença significativa entre as } \\
\text { amostras e a correlação e moderadamente } \\
\text { positiva }\end{array}$ \\
\hline Natureza & $-0,29$ & 0,057 & $\begin{array}{c}\text { Não há diferença significativa entre as } \\
\text { amostras }\end{array}$ \\
\hline Complexidade & $\mathbf{0 , 3 2}$ & $\mathbf{0 , 0 3}$ & $\begin{array}{c}\text { Há diferença significativa entre as } \\
\text { amostras e a correlação e moderadamente } \\
\text { positiva }\end{array}$ \\
\hline Tempo & $-0,14$ & 0,36 & $\begin{array}{c}\text { Não há diferença significativa entre as } \\
\text { amostras }\end{array}$ \\
\hline$\stackrel{\text { Valor }}{\text { Conclu }}$ & do as análises & $\begin{array}{c}0,54 \\
\text { quantitativas }\end{array}$ & $\begin{array}{l}\text { Não há diferença significativa entre as } \\
\text { da pesquilsamosţarrte-se agora }\end{array}$ \\
\hline
\end{tabular}

Tabela 1 - Correlações entre variáveis

Fonte: Levin (1987), software BioStat 4.0

para os resultados qualitativos das entrevistas, completando a triangulação metodológica proposta.

\section{As entrevistas}

As entrevistas semi-estruturadas, consideradas menos sistemáticas que as puramente abertas ou fechadas, (Selltiz et al. 1965), foram feitas com membros dos diversos níveis hierárquicos da área de facilities (gerente, supervidores e coordenadores que têm em média mais de 15 anos de experiência na mesma empresa) e, apesar da proximidade física que 0 grupo tem, o entendimento e a percepção sobre a missão, os objetivos, as estratégias e a relação entre o departamento e as demais áreas, variam de acordo com o nível hierárquico, o que pode denotar desalinhamento, má comunicação entre hierarquias e desintegração interna. Foram realizadas sete entrevistas gravadas e, posteriormente, apuradas, transcritas e resumidas na tentativa de extrair os principais insights dos profissionais, acerca da 
dinâmica na qual estão inseridos e suas relações com o desenvolvimento de novos produtos.

Todos concordam que não há um método formal para geração de projetos; de uma forma geral eles são oriundos das necessidades de diversos departamentos, os quais fazem as solicitações por diversos canais. Vão desde solicitações sindicais, de diretoria, de funcionários de quaisquer níveis hierárquicos, até da comunidade. Este excesso de vias de entrada é uma das principais reclamações dos faciliters (profissionais de facilities). Um dos entrevistados acrescentou: "[...] aqui parece balcão de padaria, qualquer um sai pedindo projetos”.

Em janeiro, o departamento prepara um relatório contendo todos os projetos que precisam ser executados, independentes do cliente, e por meio de reuniões técnicas internas os classificam, os priorizam e estabelecem prazos para sua execução. Ocorrem em média três reuniões oficiais com a gerência e a diretoria (corroborando com as pesquisas de Griffin $(3,8$ passos para áreas de serviços) para o go/kill. Aqui, nota-se claramente falta de sincronia e integração cross-functional, uma vez que vários projetos críticos para a organização são protelados para atender aos interesses de grupos específicos. Parece não haver uma priorização estratégica, uma vez que alguns entrevistados reclamam que alguns projetos "estéticos", como reforma de escritórios, competem com os críticos para o desenvolvimento de produtos.

A primeira grande filtragem ocorre no departamento financeiro, isto é, um primeiro grande corte, independente dos aspectos técnicos (como em ARCHER E GHASEMZADEH 1999), é feito logo nas primeiras reuniões oficiais, reduzindo em até $70 \%$ toda a verba solicitada. Esta ação cria duas situações. A primeira é que a área é obrigada a criar habilidades gerando alternativas extras e adequando seus projetos aos recursos disponibilizados. A segunda é que para driblar esta situação, muitos projetos são "quebrados" em vários anos e etapas, que na visão dos profissionais acarretaria aumento brutal dos custos, pois não são utilizados os recursos já alocados.

Após todas as revisões e seções, definem-se os projetos que realmente serão autorizados (em média 10\% a 15\% dos inicialmente previstos). Cabe a colocação de uma das entrevistadas: "[...] infelizmente 
há muitos retrabalhos na execução dos projetos por vários motivos: falta de definição clara dos clientes internos, falta de barreiras e filtros que evitem a entrada de ruídos e melhor acompanhamento dos profissionais da área de facilities". Cada projeto envolve a participação de aproximadamente 20 pessoas, dependendo do tipo de projeto, como engenheiros, técnicos de segurança, contratados, analistas, fornecedores etc. Uma vez definidos, os projetos são acompanhados semanalmente em reuniões de trabalhos. Aqui cabe ressaltar que a rede de conhecimento, apesar de extremamente tácita, é bastante dinâmica e catalisadora, pois a área gera mimetismo com a ajuda dos fornecedores que trazem soluções tecnológicas e tendências de mercado testadas em outros contratos. Exemplos disto são as soluções técnicas para redução de ruído nas prensas, queimadores de gases VOC liberados pela pintura dos veículos e novos materiais para impermeabilização de telhados e rufos.

O departamento, apesar de não estar diretamente ligado à produção de um novo produto, é crítico para a empresa como um todo, pois a qualidade de seus serviços impactam, indiscriminadamente, em todas as áreas e atividades da organização, seja pela provisão de equipamentos de escritório, suprimento de utilidades básicas como energia, ar comprimido, gás e água, pela manutenção de equipamentos e instalações já existentes ou por questões legais e governamentais. Segundo o gerente da área: "[...] eu não posso interferir na decisão da empresa, nós temos que fazer acontecer e ponto". Nota-se uma participação passiva da liderança da área nas decisões organizacionais da alta administração. Especificamente no desenvolvimento de novos produtos, facilities participa de reuniões separadas atendendo solicitações das áreas de engenharia e manufatura (fazem uso de um sistema informatizado chamado e-room, no qual todas as necessidades são inseridas para futuras considerações).

Como o departamento trabalha simultaneamente com vários projetos, percebeu-se que, embora existam barreiras e restrições internas o path dependency ou o legado da área, emprestando o termo de Danneels (2002), propicia um ambiente dinâmico e de aprendizagem contínua para o desenvolvimento de novas competências, reduzindo o tempo de execução e análise dos projetos. Diametralmente, conforme argumento de uma das 
entrevistadas: "[...] é muito estimulante desenvolver e participar de " $n$ " projetos, mas o fato é que com o tempo perdemos o foco, fazemos de tudo um pouco e não realizamos nada de concreto, só apagamos incêndio. Não temos papéis e responsabilidades bem definidos”. Além disso, a especialização torna o meio muito fechado, principalmente no segmento automotivo, estimulando mecanismos de proteção (normativos) e grupos de coalizões que barram novas idéias (muitos se tornando inclusive avessos às novidades). Há uma tênue discordância entre os papéis e responsabilidades dos funcionários da casa e os contratados, o que pode gerar disputas internas. Constatou-se também que a distribuição das atividades é uma preocupação de parte da equipe. Esta má alocação de recursos prejudica a qualidade dos projetos e aumenta o nível de insatisfação interno.

Outra barreira encontrada, típica das áreas de serviços, é com relação ao uso de ferramentas de qualidade adotadas pela empresa. Como estas geralmente nascem nos meios industriais, áreas com outras naturezas funcionais teriam dificuldades na adaptação e utilização das mesmas, tornando-as muito mais simbólicas do que funcionais. Eles afirmaram utilizar, com eficiência duvidosa, diversas ferramentas de decisão como o mapeamento da cadeia de valores, seis sigma, espinha-de-peixe e análise de falhas, entre outras.

\section{Esquema genérico do caso}

Embora não exista um esquema explícito para o desenvolvimento de projetos de facilities (notamos que se trata de um processo muito mais informal), as entrevistas e carteira de projetos sugerem um esquema genérico, como mostra a Figura 4.

$\mathrm{Na}$ Figura 4 verifica-se na faixa vertical a divisão geral do desenvolvimento de um novo produto: enquanto a matriz participa da concepção e definição dos produtos, restam para as plantas desenvolvê-los a partir das premissas de marketing, engenharia e manufatura locais (até a fase de produção em escala). Na faixa horizontal, observa-se a separação das áreas core para o desenvolvimento de novos produtos - DNP e da área de desenvolvimento de projetos de facilities - DPF. As áreas core solicitam para facilities múltiplos projetos, num canal de comunicação 


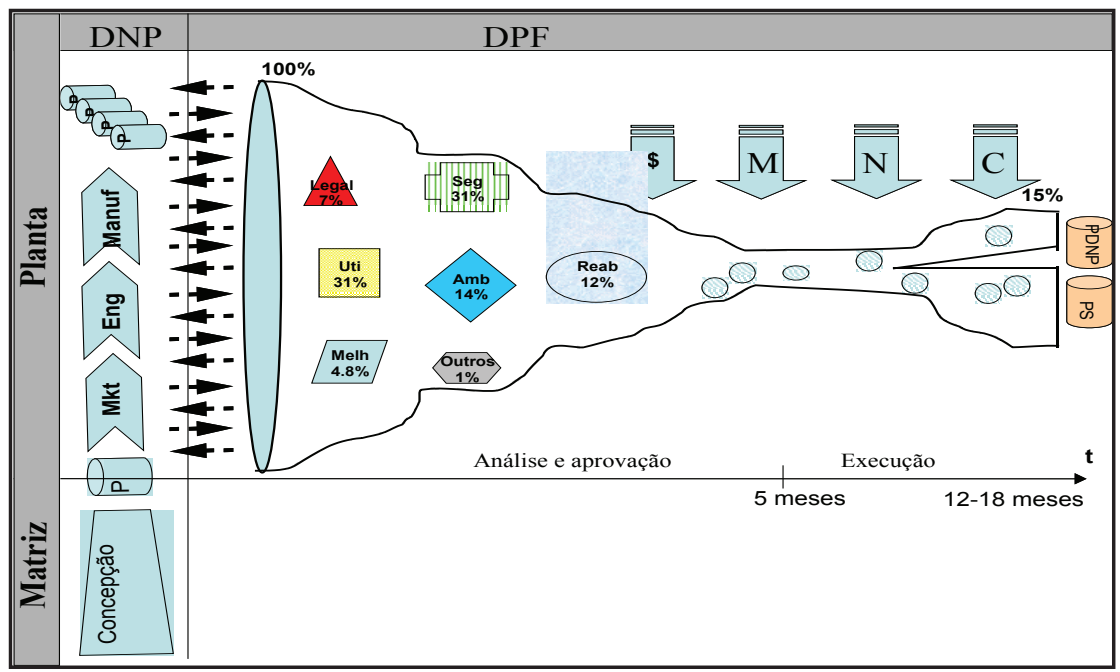

Figura 4 - Esquema genérico de funil de desenvolvimento de projetos de Facilities

Fonte elaborada pelos autores

integrado por ferramentas de softwares (e-room). A entrada do funil é muito aberta gerando uma carteira complexa para as análises e os controles dos gestores de facilities. Estes projetos são disputados internamente pelos departamentos exigindo um alto grau de atenção às decisões políticas, alocação de recursos de engenharia e troca intensa de informação (vide setas entre áreas e entrada do funil).

$\mathrm{O}$ funil vai se estreitando à medida que passa por diferentes pressões financeiras e forças institucionais ( $\mathrm{M}$ - miméticas, $\mathrm{N}$ - normativas e $\mathrm{C}$ coercitivas) criando uma zona turbulenta na entrada. Não há uma ordenação inicial ou crivo formal que selecione ou restrinja projetos não alinhados às estratégias corporativas. Este cenário demonstra o alto índice de cortes orçamentários, falta de planejamento e pré-filtros das áreas usuárias (clientes internos), desperdício de recursos de engenharia de facilities para estudar, analisar e orçar tais projetos e, principalmente, falta de alinhamento estratégico (a área poderia utilizar melhor os seus recursos nos projetos que tivessem taxa de sobrevivência maior). Percebe-se também a falta de 
mecanismos de prototipagens, o que poderia contribuir para reduzir os retrabalhos.

$\mathrm{Na}$ fase de formação da carteira, várias reuniões técnicas internas ocorrem para contemplar todas as solicitações e demandas da planta. Desenhamos este funil, analogamente, a um turbilhão dinâmico no qual as idéias e propostas entram e saem do processo na tentativa de abarcar todas as necessidades dos clientes internos (marketing, engenharia e manufatura), dentro de limitações orçamentárias e restrições tecnológicas. As seguidas pressões institucionais "estremecem" as linhas das fronteiras do funil por gerarem oscilações contínuas em função da tentativa de adaptação dos projetos às forças. Estas oscilações ocorrem paralelamente ao PDNP e refletem o ambiente incerto no qual o departamento está exposto. No fim do funil fica claro que o "produto" final de facilities é dividido em dois tipos: um (parte menor) para projetos ligados ao PDNP e outro (parte maior) para projetos diversos de sustentação e manutenção da infra-estrutura atual. De cada 100 projetos entrando apenas 15 (média) sobrevivem.

Os achados corroboram com os estudos da MPCM (2006) sobre maturidade em gestão de projetos, feitos com 21 gestores de facilities, identificando as principais barreiras na gestão. Apontaram falta de envolvimento e comprometimento das interfaces internas, ou seja, o gerente tem pouco poder formal sobre os envolvidos, existência de estrutura funcional ou matricial fraca, mudanças freqüentes nos escopos (a área não se dedica muito à fase de planejamento, gerando uma série de modificações ao longo da implantação - retrabalho), gestão de escopo incipiente com poucos controles, gerenciamento simultâneo de múltiplos projetos e dificuldade no desenvolvimento de fornecedores.

\section{CONSIDERAÇÕES FINAIS}

O esquema genérico de desenvolvimento (Figura 4) mostra a participação da GF no PDNP, evidenciando como é esta participação e em que momentos ela acontece, respondendo com isto as questões propostas na pesquisa sobre o envolvimento da área de facilities no desenvolvimento de um novo produto. A combinação de dados nos mostrou (vide setas na entrada do funil) que existe uma relação indireta, dinâmica, tácita, intermitente, intensa 
e criativa por meio de projetos subcategorizados em blocos específicos (categoria, natureza, complexidade, prioridade e tempo). Estes projetos podem estar mais próximos ou mais distantes do PDNP, atendendo tanto a construção de novas competências tecnológicas para novos produtos como a manutenção das infra-estruturas existentes.

O cenário encontrado permitiu verificar que o departamento está "órfão" num espaço "desacoplado" da estrutura organizacional e que, embora não tenha participação direta na definição de novos produtos, é responsável pela identificação dos "gargalos operacionais". Estes gargalos podem ou não serem sanados pela empresa, dependendo de interesses internos, estratégicos ou mesmo da pressão de outras forças institucionais existentes, conforme identificado na seção anterior.

A distância existente entre a área de facilities e as demais (diretamente envolvidas no PDNP) afasta o departamento das mudanças organizacionais mais radicais, mas fortalece o tecnicismo, a criatividade e o conhecimento tácito, pois os técnicos, por estarem muito tempo exercendo as mesmas funções, conhecem todos os meandros para busca de soluções. A criatividade presente na área é aflorada por constantes adequações técnicas dos projetos aos recursos existentes, geralmente ocorrendo por meio de cooperação interna ou pelos "pares" dos concorrentes do mesmo segmento de indústria.

GF concilia restrições e interesses internos às necessidades e oportunidades, num ciclo constante de ajustes e adaptações às novas estratégias e ainda que não possua relação direta com a área de desenvolvimento, sua participação é vital para que o processo de inovação aconteça de maneira sustentada.

\section{Implicações gerenciais}

Outras questões encontradas poderão ser exploradas em futuros trabalhos. A pesquisa possui algumas limitações como: pequeno tamanho da amostra dos projetos analisados; segmento específico da empresa; quantidade limitada de entrevistas e fase de transição que o departamento está passando, valendo ressaltar que, por se tratar de um estudo de caso único, os achados têm limitações de uso. Sendo assim, verificamos algumas 
lacunas que o espaço deste paper não permitiria explorar, mas que nos chamou a atenção:

- As dificuldades para se gerenciar áreas de serviços dentro de uma organização de produtos manufaturados com características completamente peculiares;

- Há necessidade do mapeamento dos caminhos (path dependencies) tácitos das áreas de serviços, bem como a geração de inovação e criatividade em ambientes paradoxais.

- Os ganhos e as perdas no gerenciamento de múltiplos projetos de serviços.

- A participação dos fornecedores como difusores do conhecimento tácito.

- A participação da área de facilities nas fases de concepção dos produtos, face à crescente demanda por sustentabilidade nos negócios.

Como citado por Danneels (2002), a inovação de produtos é o motor da renovação das organizações. Como todo motor é constituído por peças e engrenagens, podemos concluir, intuitivamente, que todas as áreas funcionais (core ou non core) são essenciais e complementares para produzirem a força necessária para girar o "eixo” da máquina organizacional inovadora.

\section{REFERÊNCIAS}

ABRAFAC - Associação Brasileira de Facilities. Documentos. Disponível em: < http://www.abrafac.com.br>. Acesso em: 20 mai 2006.

ABRAMAN - Associação Brasileira de Manutenção. $18^{\circ}$ Congresso Brasileiro de Manutenção. Porto Alegre, setembro de 2003.

ALEXANDER, K. Facilities management: theory and practice. Taylor \& Francis: United Kingdom, 1996. 
ARCHER, N. P.; GHASEMZADEH, F. An integrated framework for project portfolio selection. International Journal of Project Management, Vol. 17, No. 4, 1999, pp.207-216.

BIFM - British Institute of Facilities Management. Rethinking facilities management: accelerating change through best practices. DTI: England: 2004.

BW - Business Week, 2005. The World's Most Innovative Companies. Apr, 2006

CARVALHO, E. G. Globalização e estratégias competitivas na indústria automobilística: uma abordagem a partir das principais montadoras instaladas no Brasil. Gestão \& Produção, v.12, n.1, pp. 122-133, jan-abr, 2005.

COOPER, D. R.; SCHINDLER, P. S. Métodos de pesquisa em administração. Tradução Luciana de Oliveira de Rocha. 7. ed. Porto Alegre: Bookman, 2003, pp. 91-103.

COOPER, R.; EDGETT, S.; KLEINSCHMIDT, E. Portfolio management for new product development: results of an industry practices study. R\&D Management 31, 4, 2001, pp. 361-379.

DANNEELS, E. The dynamics of product innovation and firm competences. Strategic Management Journal, 2002, 23, 12, pp. 1095-1120.

DATAMONITOR. SWOT analysis Toyota and DaimlerChrysler, 2005. Disponível em: <www.datamonitor.com>. Acesso em: 10 maio 2007.

EASTERBY-SMITH, M.; THORPE, R.; LOWE, A. Pesquisa gerencial em Administração: um guia para monografias, dissertações, pesquisas internas e trabalhos de consultoria. São Paulo: Pioneira, 1999.

GOMORY, R. E. From the "Ladder of Science" to the product development cycle. Harvard Business Review. Nov-dec, 1989, pp. 99-105.

GRIFFIN, A. PDMA Research on new product development practices: updating trends and benchmarking best practices. Journal of Product Innovation Management, v. 14, 1997, pp. 429-458.

HAIR, J. et al. Multivariate Data Analysis. New Jersey: Prentice Hall, 1998. 
o papel da gestão de facilities...

KIM, J.; WILEMON, D. Focusing the fuzzy front-end in new product development. R\&D Management, 32, 4, 2202, pp.269-279.

KONZ, S. A. Facility design. JWS: USA, 1985.

LEVIN, J. Estatística aplicada a ciências humanas. 2. ed. Harbra: São Paulo, 1987.

LIMA, C. L et al. Fornecedores da Ford: uma avaliação preliminar das oportunidades de investimento na Bahia. set 2002. Disponível em: <www.desenbahia.ba.gov. br>. Acesso em: 20 set 2004 .

LORD, A. L.; PRICE I, S.; STEPHENSON, P. Emergent behavior in a new market: facilities management in the UK, 2001. Disponível em:< www.ifm.eng. cam.ac.uk/mcn/pdf_files/part7_1.pdf>. Acesso em: 20 jan 2006.

MALHOTRA, N. K. Pesquisa de Marketing: uma orientação aplicada. Porto Alegre: Bookman, 2001.

MANSHARAMANI, V. Towards o theory of services innovation: an inductive case study approach to evaluating the uniquess of services. Master of Science. Massachusetts Institute Technology, 2005.

MPCM- Maturity by Project Category Model. Pesquisa sobre maturidade em gestão de projetos. Prado, D.; Archibald, R. (org). Maturidade Brasil, 2006

OICA - Organisation Internationale des Constructeurs d'Automobiles. Statistics. Disponível em: < http://www.oica.net/htdocs/Main.htm>. Acesso em: 02 jan 2007.

PORTER, M. The competitive advantage of nations. The free press: New York, NY, 1990.

POWELL, W. W.; DIMAGGIO, P. J. The new institutionalism in organization analysis. Chicago: The University of Chicago Press, 1991.

QUINELLO, R.; NICOLETTI, J.R. Gestão de facilidades. São Paulo: Novatec, 2006.

ROSS, E. A. The location of industries. The Quarterly Journal of Economics, April, pp. 247-268, 1896. 
revista tecnologia e sociedade

SELLTIZ et al. Métodos de pesquisa nas relações sociais. São Paulo: Herder, 1965.

SHORET, I. M.; LAVY-LEIBOVICH, S.; BAR-ON, D. Integrated maintenance monitoring of hospital buildings. Construction management and economics, n. 21, 2003, pp. 219-228.

WHEELWRIGHT, S.; CLARK, C. Creating project plans to focus product development. Harvard Business Review, Cambridge, Ma., Mar-Apr, 1992, pp.70-82. 